\title{
Magic Clips for Fixed Retention
}

\author{
Dr. Amit Prakash,' Dr. Satish Chamania, ${ }^{2}$ Dr. Prabhuraj B.Kambalyal, ${ }^{3}$ Dr.Shashi Bhusan Ekka ${ }^{4}$ \\ 1.4Reader, Dept of Orthodontics, Peoples College of Dental Science, Bhopal \\ ${ }^{2}$ Senior Lecturer, Dept of Orthodontics, Gurugobind Singh Dental College, Burhanpur \\ 3Professor, Dept of Orthodontics, Darshan Dental College, Udaipur, India
}

Correspondence: Dr Amit Prakash; Email: amitprakash3o@gmail.com

\section{ABSTRACT}

Despite major advances in orthodontic tooth movement, orthodontic retention remains a major problem. It has been estimated that only $10 \%$ of the population who have received orthodontics are still in acceptable occlusion as judged by orthodontists 20 years after retention. One of the means of maintaining stability has been the use of fixed retainers. This article will describe a very simple and effective method of stabilizing the retainer during bonding using clip. The method of stabilizing the fixed retainer described in this article is the most simplest, economical, least time consuming and also very effective method.

Keywords: Magic Clip, Orthodontics, Retention

\section{INTRODUCTION}

A bonded/fixed retainer is very useful, especially in cases which require permanent retention to avoid any relapse tendencies.' There are three generation of bonded retainer used in orthodontics for retention after orthodontic treatment. ${ }^{2-3}$ Various methods have been used for stabilization in past such as ligature wire, silicone based impression trays, elastics etc. In this article, a simple technique of placing an upper and lower fixed retainer is explained. The magic clip used in this article is used for holding the wire during bonding of retainer.

\section{FABRICATION PROCEDURE}

Take upper and lower impression after debonding the appliance. Pour it with dental stone. Wire bending of magic clip done with 0.018 AJW SS wire. It consists of two arms (A and B) separated by a U-bend of $2 \mathrm{~mm}$ internal diameter. B arm consist of a $U$ loop of $2 \mathrm{~mm}$ internal diameter and Vertical arm of $8 \mathrm{~mm}$ (Figure 1, 2, 3).

\section{BONDING RETAINER PROCEDURE}

A bonded retainer can be fabricated with 0.0175 twist flex wire, 0.0215 inch five stranded wire, $0.016 \times 0.022$ inch dead

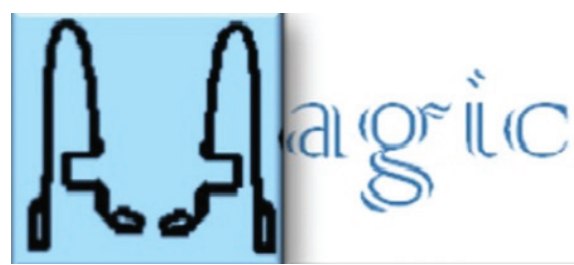

Figure 1: Magic clips

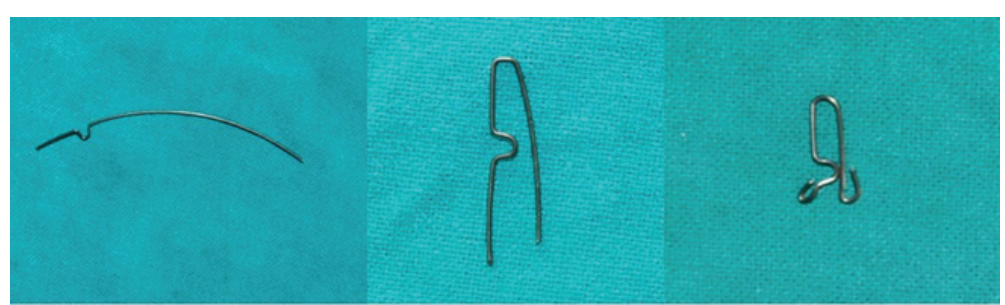

Figure 2: Wire bending procedure

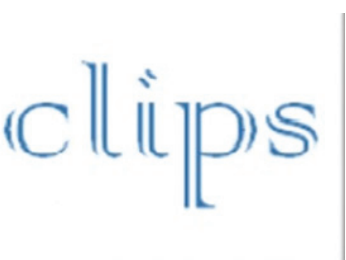

" $U$ " bend
" $A$ " arm “B” arm "U" loop

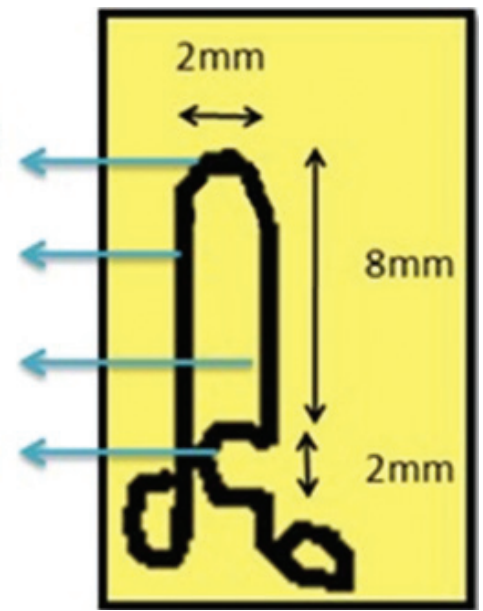

Figure 3: Dimensions in magic clip 


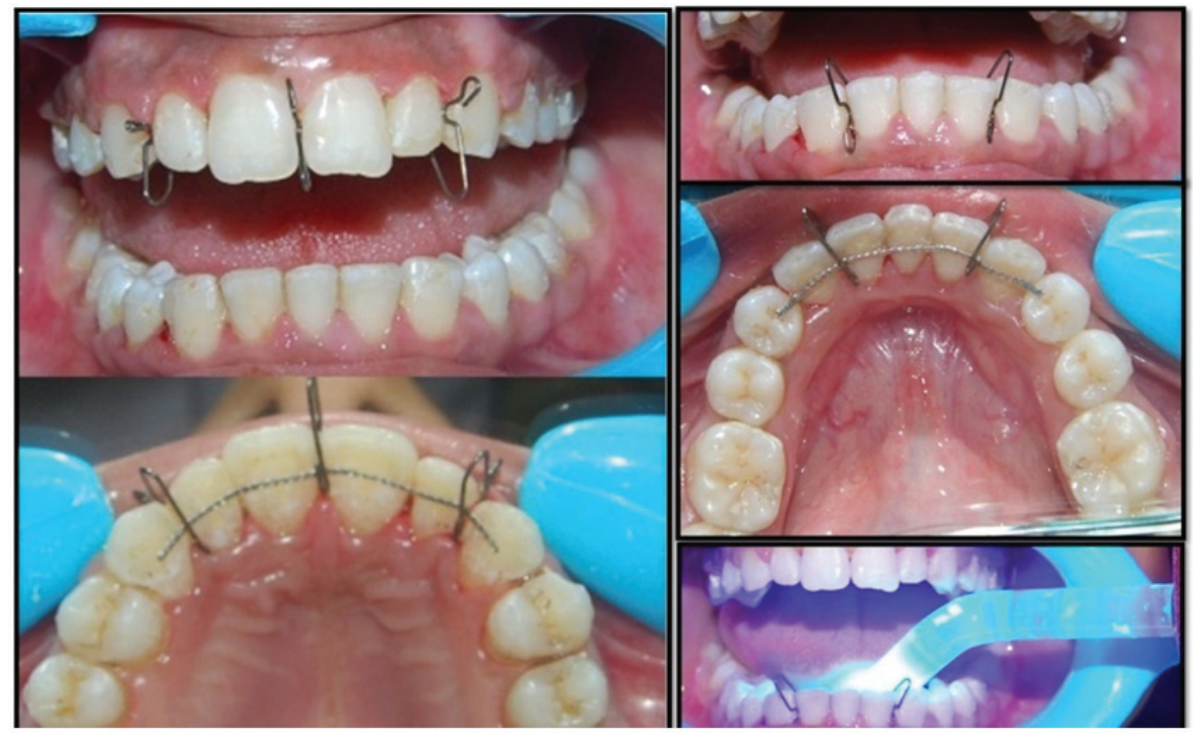

Figure 4: Intraoral used during fixation of retainer

soft braided wire, 0.0195 inch dead soft co-axial wire, twisted 0.09 or 0.010 ligature wire. ${ }^{2-3}$ The preformed wire is first placed passively on the lingual surfaces of upper and lowers canine to canine and stabilized with magic clips. Number of clips used varies from 2-3. Generally upper and lower arch requires 3 and 2 clips respectively. Following 10-15 seconds pumicing, the lingual surfaces of canine to canine are etched for 30 seconds. We find Transbond H L.C. is a good composite to use because of the high filler content, reducing the risk of failure. After carefully drying the teeth with moisture and oil-free air, an etched appearance can be seen on all six lower anterior teeth. A small amount of composite needs to be placed on the lingual surface of lower 3-3 and subsequently cured (Figure 4). The amount of composite should be big enough to cover the wire only in the middle of the crown and not all the way along the crown surface. It must be stressed that a good moisture control is an absolute requirement for successful use of a bonded retainer. The patient is then given specific oral hygiene instruction on how to use super floss under the retainer. However, they should be told to return urgently should one of the bonds become loose.

\section{ADVANTAGE}

- Accurate, effective and predictable

- Easy to make and cost effective

- Wire used is resilient and easy to manipulate

- Reduces chair-side time

- Less armamentarium needed

- No laboratory work required

- It can be reused after sterilization.

\section{REFERENCES}

1. Bearn DR. Bonded orthodontic retainers: A review. Am J Orthod. 1995; 108:207-13.

2. Lim SM. Hong RK, Park JY. A new indirect bonding technique for lingual retainers. J Clin Orthod. 2004; 38:652-5.

3. Zachrisson BU. Clinical experience with direct bonded orthodontic retainers. Am J Orthod. 1977; 71:440-8. 